\title{
CORPOS INFANTIS NA CONTEMPORANEIDADE: DESLOCAMENTOS E SUBJETIVIDADES NA POLÍTICA NACIONAL DE ALFABETIZAÇÃO
}

\author{
CHILDREN INDIVIDUALS IN CONTEMPORANEITY: DISPLACEMENTS AND SUBJECTIVITIES IN THE NATIONAL \\ LITERACY POLICY \\ CUERPOS INFANTILES EN LA CONTEMPORANEIDAD: DESPLAZAMIENTOS Y SUBJETIVIDADES EN LA POLÍTICA \\ NACIONAL DE ALFABETIZACIÓN
}

\author{
DUTRA, Isabela1 \\ MACHADO, Roseli Belmonte2
}

\section{RESUMO}

Pensar a infância significa descontruir uma imagem única, reconhecer sua potência múltipla e refletir sobre as subjetividades que vem sendo constituídas. Assim, esta pesquisa objetivou refletir sobre os lugares e as subjetividades que vem sendo produzidas sobre os corpos infantis incluídos nas escolas regulares brasileiras. Para tanto, analisamos documentos sobre a infância e a escola nos últimos tempos, além de analisar a Política Nacional de Alfabetização, de 2019. É um estudo inspirado nos Estudos Foucaultianos, com base nos conceitos de governamento e governamentalidade. Consideramos que está se anunciando deslocamentos na produção de subjetividades para os corpos infantis nas escolas.

Palavras-chave: Infância. Escola. Governo. Política Nacional de Alfabetização.

\section{ABSTRACT}

Thinking about the childhood means deconstructing a unique image, recognizing its multiple potency and reflecting about the subjectivities that have been constituted. Therefore, this paper has intended to reflect about the places and the subjectivities which have been produced about the children individuals included in Brazilian regular schools. For this purpose, we have analyzed documents about the childhood and the school in recent times, besides analyzing the National Literacy Policy, from 2019. This is a study inspired in Foucaultian Studies, based on the concepts of governance and governmentality. We consider displacements are coming in the production of subjectivities to the children individuals in the schools.

Keywords: Childhood. School. Government. National Literacy Policy.

\section{RESUMEN}

Pensar la niñez significa descontruir una imagen única, reconocer su potencialidad y reflexionar acerca de las subjetividades que están siendo constituidas. Por lo tanto, esta investigación objetivó reflexionar acerca de los sitios y las subjetividades que son producidas acerca de los cuerpos infantiles incluidos en las escuelas regulares brasileñas. Para eso, analizamos documentos acerca de la niñez y las escuelas en los últimos tiempos, además de hacer un análisis de la Política Nacional de Alfabetización, de 2019. Es un estudio inspirado en los estudios Focaultianos, basado en los conceptos gubernamentales y de gubernamentalidad. Consideramos que está anunciándose desplazamientos de subjetividad para los cuerpos infantiles en las escuelas.

Palabras clave: Niñez. Escuela. Gobierno. Política Nacional de Alfabetización.

\footnotetext{
${ }^{1}$ Universidade Federal do Rio Grande do Sul - UFRGS - Porto Alegre - Rio Grande do Sul - Brasil.

${ }^{2}$ Universidade Federal do Rio Grande do Sul - UFRGS - Porto Alegre - Rio Grande do Sul - Brasil.
} 


\section{INTRODUÇÃO}

O que é a infância? A pergunta ressoa sem parar. Será que conseguimos levara interrogação até onde ela consiga, de verdade, fazermo-nos interrogar?

(KOHAN, 2004, p. 51)

Iniciamos este texto com a provocação feita por Kohan ao questionar "o que é a infância?". Na incompletude de definir esse conceito, perguntamo-nos sem cessar: afinal, o que é isso ou aquilo? Wittgeinsten (1999) contribuiu de forma significativa no entendimento de que a definição da "coisa em si" é insuficiente para pensarmos as relações entre fatos ou acontecimentos, pois trata-se de uma relação sempre contigencial. Essa virada na forma de compreender os jogos de linguagem abandona a visão tradicional de que a palavra em si carrega uma definição e nos leva a compreender que é preciso olharmos para o único a priori que existe, o histórico, ou seja, perceber em que contextos sociais, políticos, econômicos e culturais determinados conceitos emergiram. No caso deste estudo, nos interessa compreender de que forma os corpos infantis vêm sendo produzidos na Contemporaneidade e, mais especificamente, refletir sobre os lugares e as subjetividades que podem ser forjadas nas escolas regulares brasileiras, a partir da Política Nacional de Alfabetização. Para tanto, é preciso colocar em suspenso uma concepção única e verdadeira sobre o que é a infância e pensar na sua potência múltipla e diversa, que desde a Modernidade vem se constituindo como objeto de estudo e investimento.

De forma muito significativa, os estudos sobre infância e inclusão se intercruzam quando olhamos para os cenários escolares e percebemos que falar em sujeitos infantis incluídos estava, até então, na ordem do dia dentro da lógica de uma governamentalidade neoliberal. Entretanto, alguns deslocamentos têm direcionado e constituído outras formas de pensar a inclusão desses corpos na escola, produzindo outras formas de ser sujeito infantil na Contemporaneidade. Tal reflexão será problematizada dentro de uma perspectiva pós-estruturalista, inspirada nos Estudos Foucaultianos em Educação. Nesse sentido, este artigo se organiza em quatro seções, sendo uma primeira metodológica que anuncia os conceitos que sustentam essa pesquisa, bem como apresenta os dois movimentos de análise feitos neste percurso. Na segunda seção, apresentamos alguns caminhos sore educação, infância e inclusão, no sentido de pensarmos de que forma a infância vem se constituindo como objeto de investimento e preocupação social, a partir da análise de documentos como a Constituição Federal de 1988, Estatuto da Criança e do Adolescente (ECA), de 1990 e o programa Primeira Infância Melhor (PIM), de 2006. Já na terceira seção, discutimos alguns deslocamentos trazidos no texto da Política Nacional de Alfabetização sobre aquilo que vem sendo pensado para os sujeitos infantis a partir de duas categorias analíticas: a) ciência acima de tudo e b) onde está a cultura? Por fim, refletimos sobre os principais impactos dessas concepções que vêm se anunciando, no que diz respeitos à constituição de outras subjetividades infantis na Contemporaneidade.

\section{PERCURSO DE PESQUISA}


Baseado numa ideia que identifica a presença da inclusão dos diferentes corpos infantis nas escolas regulares, nos debruçamos a analisar como fomos nos constituindo em uma sociedade que, até então, no bojo de uma governamentalidade neoliberal, considerando seus efeitos, buscava incluir as diversas infâncias na escola. Importa afirmar que tomamos como inclusão na escola a busca por colocar no espaço escolar os diferentes corpos infantis, considerando as diferenças étnico-racias, de gênero, de condições sócio-econômicas, de pluralidade religiosa e de distintas características físicas. Contudo, nos tempos atuais, temos percebido um deslocamento nessa busca pela inclusão desses corpos na escola e, mais do que isso, na permanência desses corpos e, a partir disso, nos preocupa os rumos futuros da infância na escola. Dentro desse âmbito, o objetivo da pesquisa foi o de refletir sobre os lugares e as subjetividades que vem sendo produzidas sobre os corpos infantis incluídos nas escolas regulares brasileiras.

É preciso sublinhar que este estudo está inscrito numa perspectiva pós-estruturalista, a qual, como já destacava Silva (1994), trata-se de uma perspectiva que "reconhece o descentramento da consciência e do sujeito, a instabilidade e provisoriedade das múltiplas posições em que são colocados pelos múltiplos e cambiantes discursos em que são constituídos, começa por questionar e interrogar esses discursos" (SILVA, 1994, p. 14). A pesquisa foi realizada a partir de dois movimentos. O primeiro tratou de uma atividade de pesquisa de inspiração genealógica a qual, para Foucault (2010) seria "uma espécie de empreendimento para dessujeitar os saberes históricos e torná-los livres, isto é, capazes de oposição e de luta contra a coerção de um discurso teórico unitário, formal e científico conjunto" (FOUCAULT, 2010, p. 15-16). A partir de um investimento com tal inspiração, compreendemos ser possível analisar as condições de possibilidade para a emergência de certas práticas sobre os corpos infantis incluídos na escola e que nos constitui e nos conduz nas relações entre saber, poder e verdade. Assim, a fim de compreender como os diferentes corpos infantis vêm habitando a escola foi realizado um recuo por intermédio da análise de documentos que foram constituindo a infância e a educação no Brasil. Dentre eles, destacam-se a Constituição Federal de 1988, o Estatuto da Criança e do Adolescente e o Programa Primeira Infância Melhor. Já o segundo movimento de pesquisa tratou de examinar a recente política, intitulada de Política Nacional de Alfabetização, publicada em 2019.

É preciso dizer que o olhar para essas questões foram possíveis a partir de lentes teóricas que nos constituem dentro dos Estudos Foucaultianos em Educação. Para Veiga-Neto (2016):

\footnotetext{
Por conta do "olhar", fica o entendimento de que se pode ir à oficina de Foucault para apenas apanhar algumas de seus conceitos-ferramenta ou para, ali, respirar a atmosfera que o filósofo deixou à nossa disposição. Em qualquer caso, busca-se, no seu pensamento, o estranhamento frente ao lugar-comum; buscam-se, também, outras maneiras possíveis de significar tudo aquilo que já parecia ter um significado sólido, acabado, tranquilo e bem sabido. (VEIGA-NETO, 2016, p. 4).
}

Embasadas por esses estudos, os principais conceito-ferramentas utilizados foram o de governamento e governamentalidade. Tais conceitos foram escolhidos por nos permitirem compreender como somos conduzidos, constituídos e governados e, ao mesmo tempo, perceber como nos constituímos, conduzimos e governamos em distintas racionalidades.

Para esta pesquisa, nos apoiamos na compreensão de governamentalidade a partir do que Michel Foucault trouxe no curso Nascimento da Biopolítica, ministrado em 1979 no Collége de France. 
O autor realiza uma análise sobre os modos de exercício de governo a partir da égide da governamentalidade e afirma: "o que propus chamar de governamentalidade não é mais que uma proposta de grade de análise para essas relações de poder" (FOUCAULT, 2008, p. 258). Castro (2009) fala-nos que a governamentalidade abarca, num sentido amplo, o exame das chamadas "artes de governar", que incluem o estudo do governo de si (ética), o governo dos outros (as formas políticas da governamentalidade) e as relações entre o governo de si e o dos outros. Foucault marca uma interdependência entre o exercício do governamento (práticas) e as mentalidades que sustentam as práticas. Nessa proposta, cabe ressaltar o sentido da expressão governamento. Veiga-Neto (2002) trata de governamento dizendo que, diferentemente da forma conhecida da palavra governo geralmente grafada com $\mathrm{G}$ maiúsculo -, ligada à administração pública, a palavra governamento inclui as diversas formas de governar.

Portanto, nesta pesquisa, compreendemos que governamentalidade e governamento são profícuas ferramentas para analisar nosso objeto de pesquisa, auxiliando na compreensão e na problematização sobre os deslocamentos na forma como os corpos infantis são constituídos, conduzidos e governados em suas relações com a escola.

Não obstante, marcamos a presença de um importante conceito que atravessa esta pesquisa, que é o de subjetividade. Para tanto, nos apoiamos nas palavras de Foucault (2004): "Eu chamaria de subjetivação o processo pelo qual se obtém a constituição de um sujeito, mais precisamente de uma subjetividade, que evidentemente não passa de uma das possibilidades dadas de organização de uma consciência de si" (FOUCAULT, 2004, p. 262). Nessa perspectiva, nos lançamos a refletir sobre as constituições e possíveis deslocamentos dos processos de subjetivação dos sujeitos infantis nas escolas regulares.

\section{EDUCAÇÃO, INFÂNCIA, INCLUSÃO - ALGUNS CAMINHOS}

A escola, na sociedade atual, ainda é legitimada como a principal instituição responsável pela transmissão de saberes acumulados (FABRIS, 2014). Essa afirmação ainda vem forte e carregada de significados, embora estejamos em meio a uma crise das instituições e de muitos questionamentos sobre o papel da escola nos dias de hoje. Um aspecto que corrobora a importância e necessidade da escola é que ela é obrigatória, ou seja, as crianças devem ir à escola, sendo esta condição "prevista pela legislação e todas as políticas de inclusão que asseguram a escola para todos" (FABRIS, 2014, p.48). Quando nos deparamos com a ideia de que todos devem estar na escola, temos as diferenças habitando o espaço escolar. Entretanto, a ideia de ensinar a todos não é recente, mas sim acompanha todo o ideal de escolar moderna.

É na Modernidade que vemos emergir um sentimento de infância quando há um interesse psicológico e de preocupação moral sobre estes sujeitos (ARIĖS, 2014). Se até então ela era vista como uma imagem em miniatura do adulto em meio ao convívio privado da família, nesse momento ela começa a ser percebida como parte de um grande corpo coletivo, "como um ser inacabado, carente e, portanto individualizado, produto de um recorte que reconhece nela a necessidade de resguardo e proteção" (NARODOWSKI, 2001, p. 27). Entretanto, ainda não se falava em outros termos, como em 
uma cultura da infância, por exemplo. Embora existisse um olhar para esses sujeitos, ainda era como forma de garantir que se tornassem bons adultos, capazes de attender às demandas da sociedade burguesa em emergência. Nesse contexto, era preciso formar esses futuros adultos, o que acaba por deslocar a criança para dentro das instituições escolares, as quais se constituem como grandes maquinarias de transformação desses corpos e como produtoras de subjetividades:

[...] a educação, notadamente a escolar, é uma forma de territorialização da subjetividade, isto é, uma forma de subjetivação. A educação, sobretudo a escolarizada, investe numa serialização, para usar um conceito sartriano, isto é, num processo de formação de subjetividades em série, reproduzindo-se a si mesmas como que curto-circuitando o movimento, fazendo com que ele se torne um "eterno retorno do mesmo". (GALLO, 2005, p. 214).

$\mathrm{Na}$ Contemporandeidade, a inclusão dos diferentes sujeitos infantis nos espaços escolares, a partir das políticas de inclusão, vem sendo entendida como uma prática que tem por objetivo o gerenciamento de riscos, ou seja, incluir para melhor governar e como possibilidade de melhores condições de vida no âmbito social e econômico.

[...] para analisar a inclusão não basta mapear o presente a partir de coleta de políticas, leis regulamentos, histórias de vida, testemunhos, estatísticas, etc. É condição para entender sua emergência focar acontecimentos passados, buscando estabelecer, sempre de forma arriscada e perigosa, relações entre acontecimentos aparentemente desconexos, mas que são capazes de nos fazer entender aquilo que nos tornamos, aquilo pelo que lutamos e aquilo que acreditamos no presente. (LOPES; FABRIS, 2013, p. 19).

Nas últimas três décadas temos percebido uma proliferação de políticas que posicionam o infante como sujeito de direito, como por exemplo, a Constituição Federal de 1988, Estatuto da Criança e do Adolescente (BRASIL, 1990) e o programa Primeira Infância Melhor (RIO GRANDE DO SUL, 2006). Essas práticas ratificam a ideia de que todas as crianças têm o direito à educação pública, laica e de qualidade e devem estar incluídas na escola. Paralelamente a isso, vemos a emergência do campo da sociologia da infância, o qual passa a disputar saberes com a psicologia e a medicina, mas que somente na década de 1990 se constitui com um campo de estudos no Brasil. Segundo Sarmento (2005) "a sociologia da infância propõe-se a interrogar a sociedade a partir de um ponto de vista que toma as crianças como objecto de investigação sociológica por direito próprio" (SARMENTO, 2005, p. 363). Se até a década de 80 os sujeitos infantis eram pensados e constituídos para se tornarem bons adultos, a partir da sociologia da infância, há um deslocamento da figura do adulto para uma maior centralidade na infância. Ou seja, os diferentes tempos da infância passam a ser respeitados e se potencializa o protagonismo desses sujeitos quando os pensamos com produtores de cultura.

As concepções de infância manifestadas nos documentos oficiais, como a Constituição Federal de 1988, Estatuto de Criança e do Adolescente e ao Programa Primeira Infância Melhor, reforçam a ideia de que vivemos tempos em que os sujeitos infantis são olhados e pensados de forma a garantir seus direitos. Nesse período, a Constituição Federal de 1988 se apresenta como um marco social, uma vez que traz em seu bojo a ampliação dos direitos civis e as garantias fundamentais dos cidadãos, bem como elenca como prioridade os direitos das crianças e adolescentes. Há um enorme alargamento no que diz respeito à criança ou infância. Há 55 citações sobre o assunto e, concordamos que "[...] até a Constituição de 1969, a criança não era tratada como sujeito de direitos, sendo seguida a teoria da 
situação irregular, contida no Código de Menores, tendência essa rompida com a Constituição de 1988 e complementada com a edição do Estatuto da Criança e do Adolescente (ECA)" (COELHO, 1998, p. 94). A Constituição de 1988 garante a proteção integral à criança e ao adolescente pelo artigo 227:

É dever da família da sociedade e do Fstado assenurar à crianca ao adolescente e ao iovem. com absoluta prioridade. o direito à vida. à saúde. à alimentacão. à educacão. ao lazer. à nrofissionalizacão à cultura à dianidade. an resneito à liberdade e à convivência familiar $e$ comunitária. além de colocá-los a salvo de toda forma de negligência, discriminação, exploração, violência, crueldade e opressão. (BRASIL, 1988).

A promulgação do Estatuto da Criança e do Adolescente corrobora a política de proteção integral dos sujeitos infantis e é considerado um dos marcos legais da garantia de direitos desses sujeitos. Scheinvar (2015) caracteriza o ECA como a "expressão da potência subjetiva do Estado de Direito e, como toda lei, uma formação discursiva" (p. 104). Esse novo olhar colocado sobre a infância garate a ela o direito à educação, o qual deve ser provido pelo Estado e família, conforme artigo 205 da Constituição Federal de 1988 e que especifica, nos artigos subsequentes, quais são os princípios que deverão nortear o processo educativo:

Art. 205. A educação, direito de todos e dever do Estado e da família, será promovida e incentivada com a colaboração da sociedade, visando ao pleno desenvolvimento da pessoa, seu preparo para o exercício da cidadania e sua qualificação para o trabalho.

Art. 206. O ensino será ministrado com base nos seguintes princípios:

I - igualdade de condições para o acesso e permanência na escola;

II - liberdade de aprender, ensinar, pesquisar e divulgar o pensamento, a arte e o saber;

III - pluralismo de ideias e de concepções pedagógicas, e coexistência de instituições públicas e privadas de ensino;

IV - gratuidade do ensino público em estabelecimentos oficiais;

V - valorização dos profissionais da educação escolar, garantidos, na forma da lei, planos de carreira, com ingresso exclusivamente por concurso público de provas e títulos, aos das redes públicas;

VI - gestão democrática do ensino público, na forma da lei;

VII - garantia de padrão de qualidade;

VIII - piso salarial profissional nacional para os profissionais da educação escolar pública, nos termos de lei federal.

Parágrafo único. A lei disporá sobre as categorias de trabalhadores considerados profissionais da educação básica e sobre a fixação de prazo para a elaboração ou adequação de seus planos de carreira, no âmbito da União, dos Estados, do Distrito Federal e dos Municípios.

- $\quad$ Art. 208. O dever do Estado com a educação será efetivado mediante a garantia de:

I - ensino fundamental obrigatório e gratuito, assegurada, inclusive, sua oferta gratuita para todos os que a ele não tiverem acesso na idade própria;

II - progressiva universalização do ensino médio gratuito

III - atendimento educacional especializado aos portadores de deficiência, preferencialmente na rede regular de ensino;

IV - atendimento em creche e pré-escola às crianças de zero a seis anos de idade;

V - acesso aos níveis mais elevados do ensino, da pesquisa e da criação artística, segundo a capacidade de cada um;

VI - oferta de ensino noturno regular, adequado às condições do educando;

VII - atendimento ao educando, no ensino fundamental, através de programas suplementares de material didático-escolar, transporte, alimentação e assistência à saúde.

$\S 1^{\circ} \mathrm{O}$ acesso ao ensino obrigatório e gratuito é direito público subjetivo.

$\$ 2^{\circ} \mathrm{O}$ não-oferecimento do ensino obrigatório pelo poder público, ou sua oferta irregular, importa responsabilidade da autoridade competente.

$\S 3^{\circ}$ Compete ao poder público recensear os educandos no ensino fundamental, fazer-lhes a chamada e zelar, junto aos pais ou responsáveis, pela frequência à escola.

O programa Primeira Infância Melhor (PIM), de 2006, é uma política pública pioneira no que diz respeito às suas práticas e se tornou referência no Brasil: são realizadas visitas domiciliares e comunitárias com o objetivo de garantir que os direitos à saúde, educação e demais cuidados destinados às crianças, principalmente em condição de vulnerabilidade social, estejam sendo 
atendidos. Esta política compõe uma das principais ações do Governo do Rio Grande do Sul e é reconhecida a nível federal como uma das políticas mais consistentes voltadas para a Infância da América Latina.

É possível notar que há uma busca pela inclusão dos sujeitos infantis no cenário político, econômico, social e cultural, a partir da década de 1980. Nessa direção, falamos que há uma condução das condutas desses sujeitos quando passam a ser alvo de diferentes investimentos na Contemporaneidade. Uma condução das condutas, um governamento dos sujeitos, no sentido de constituir um infante e um futuro adulto implicado com as questões sociais, éticas, ambientais e que vivesse, valorizasse e respeitasse a pluralidade de ideias, de crenças, de constituição étnico-racial, de gênero, de condições sociais e de diferenças físicas. A governamentalidade neoliberal, nesse sentido, buscava, por intermédio de estratégias inclusivas, trazer a todos para a escola e, desse modo, também incluí-los nas diversas redes de mercado.

Ao olhar para esses sujeitos dentro da escola, é preciso problematizarmos de que forma suas subjetividades estão sendo constituídas e portanto, de que forma pensamos essa relação educação, infância e inclusão hoje. É nesse movimento, que optamos por refletir sobre a Política Nacional de Alfabetização, que traz em seu texto, concepções que norteiam as práticas direcionadas à educação no cenário atual.

\section{EDUCAÇÃO, INFÂNCIA, INCLUSÃO - RUMOS ATUAIS}

Entender como fomos nos constituindo é condição fundamental para refletir sobre quem somos e problematizar as possibilidades futuras. Nessa perspectiva é preciso dizer que compreendemos que, no bojo de uma governamentalidade neoliberal brasileira, vínhamos vivendo o objetivo de incluir os diferentes corpos infantis na escola - em que pese os efeitos dessa busca -, e que, no momento atual, outros caminhos vêm se anunciando. Essa afirmação está baseada em atuais publicações do Governo Federal brasileiro, o qual projeta outros rumos para os corpos infantis na escola. Uma dessas publicações, que materializa as intenções e discursos do atual Governo Federal brasileiro, é a Política Nacional de Alfabetização ${ }^{3}$ (PNA), divulgada pelo decreto $n^{\circ} 9.765$ de 11 de abril de 20194, sobre a qual nos debruçamos a realizar uma análise no intento de problematizar como são pensadas as subjetividades dos corpos infantis a partir dessa proposta.

Para começar, apresentamos considerações sobre a estrutura e objetivo principal dessa Política, Logo após, abordamos duas questões que, neste momento, entendemos como pertinentes para compor esta análise. Essas duas questões são categorias de análise, as quais foram nomeadas como Ciência acima de tudo e Onde está a cultura. Importa dizer que outros pontos estão sendo problematizados a partir da análise dessa política, mas, para esta produção, nos dedicamos a contribuir com as questões supracitadas, as quais, passamos a discorrer.

\footnotetext{
${ }^{3}$ Disponível em: http://portal.mec.gov.br/images/CADERNO_PNA_FINAL.pdf Acesso em 27 de outubro de 2019.

${ }^{4}$ Disponível em: http://www.planalto.gov.br/ccivil_03/_ato2019-2022/2019/decreto/D9765.htm Acesso em 27 de outubro de 2019.
} 
Em 11 de abril de 2019, o Governo Federal brasileiro publica o decreto $n^{\circ}$ 9.765, o qual institui a Política Nacional de Alfabetização. Em seu artigo $1^{\circ}$ coloca:

Art. $1^{\circ}$ - Fica instituída a Política Nacional de Alfabetização, por meio da qual a União, em colaboração com os Estados, o Distrito Federal e os Municípios, implementará programas e ações voltados à promoção da alfabetização baseada em evidências científicas, com a finalidade de melhorar a qualidade da alfabetização no território nacional e de combater o analfabetismo absoluto e o analfabetismo funcional, no âmbito das diferentes etapas e modalidades da educação básica e da educação não formal. (BRASIL, 2019).

Esse decreto, composto de 14 artigos, dispõe sobre princípios, objetivos, diretrizes, públicoalvo e agentes envolvidos com a Política Nacional de Alfabetização. Além disso, trata da implementação, avaliação e monitoramento dessa política trazendo, ao mesmo tempo, um vocabulário específico de termos que serão usados para compreender as ações do Ministério da Educação - que assina o decreto - no tocante às ações para efetivar essa proposta.

Após esse decreto, o Ministério da Educação, através da Secretaria de Alfabetização, lança um documento chamado Política Nacional de Alfabetização (BRASIL, 2019a), o qual especifica os objetivos e ações dessa política, a partir de uma contextualização e linha do tempo que, na página 15 , está na forma de uma ilustração. Vejamos essa linha do tempo:

\section{Linha do Tempo: Política Nacional de Alfabetização}

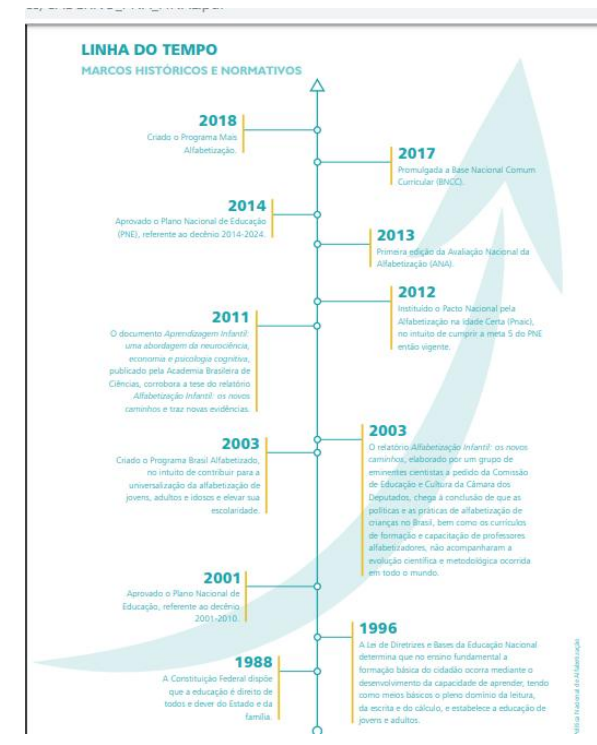

Fonte: http://portal.mec.gov.br/images/CADERNO_PNA_FINAL.pdf (BRASIL, 2019a)

Para compreendermos como tal política foi pensada, precisamos refletir sobre os marcos utilizados como balizadores de tal proposta. Ao analisarmos a linha do tempo (imagem acima) vemos que os documentos citados são: a Constituição Federal de 1988; a Lei de Diretrizes e Bases da Educação de 1996; o Plano Nacional de Educação 2001-2010; o Programa Brasil Alfabetizado de 2003; o chamado relatório de Alfabetização Infantil de 2003 que, de acordo com o documento "elaborado por um grupo de eminentes cientistas a pedido da Comissão de Educação e Cultura da 
Câmara dos Deputados, chega à conclusão de que as políticas e as práticas de alfabetização de crianças no Brasil, bem como os currículos de formação e capacitação de professores alfabetizadores, não acompanharam a evolução científica e metodológica ocorrida em todo o mundo"; o documento Aprendizagem Infantil, com uma abordagem da neurociência, de 2011; o Pacto Nacional de Alfabetização na Idade Certa (Pnaic) de 2012; a primeira edição da Avaliação Nacional de Alfabetização (ANA) de 2013; o Plano Nacional de Educação 2014-2024; a Base Nacional Curricular Comum publicada em 2017 e o Programa Mais Alfabetização de 2018. Nota-se que foi trazido um referencial que, em sua costura, busca mostrar uma falha nos processos de alfabetização no Brasil e, ao mesmo tempo, valoriza relatórios que são do domínio de um padrão biológico do sujeito.

A análise das considerações gerais sobre o objetivo e implantação da Política Nacional de Alfabetização nos conduziu a formular uma categoria de análise que nomeamos como Ciência Acima de Tudo. Uma das questões que nos chamou a atenção foi o fato dessa política se remeter, a todo o momento, a uma ideia de "ciência". Uma ciência grafada assim mesmo, no singular. Uma expressão que refere a uma unicidade científica, como se existisse uma única ciência ou uma única verdade científica. Buscar uma única verdade científica vai na contramão do entendimento que temos de que não há uma verdade absoluta e que o sentido que atribuímos às coisas é que as constituem. Como já trazemos em Wittgeinsten (1999), sobre a "coisa em si", reduz as formas de pensamento. Foucault (2010) traz que a verdade é indissociável da singularidade, portanto é contingencial, é relacional. Diante dessas questões, nos perguntamos: qual verdade científica é sustendada na PNA? Logo na apresentação do documento, destaca-se a preocupação em:

[...] inserir o Brasil no rol de países que escolheram a ciência como fundamento na elaboração de suas políticas públicas de alfabetização, levando para a sala de aula os achados das ciências cognitivas e promovendo, em consonância com o pacto federativo, as práticas de alfabetização mais eficazes, a fim de criar melhores condições para o ensino e a aprendizagem das habilidades de leitura e de escrita em todo o país. (BRASIL, 2019a, p.7).

Quando se fala em incluir o Brasil na lista de países que escolheram a ciência, compreendemos que o documento quer dizer que, até então, as políticas públicas voltadas para a educação, não eram baseadas ou fundamentadas em conhecimento científico e, portanto ineficazes. No documento: a PNA "é consequência de uma realidade educacional que revela a urgência de mudança na concepção de políticas voltadas à alfabetização, à literacia e à numeracia" (BRASIL, 2019a, p.10). Além disso, questionamos qual ciência o documento aborda e, mais do que isso sublinhamos a inclinação para uma ideia de um tipo de ciência no âmbito somente cognitivo. Como nos lembra Foucault (2016) "não se pode, assim me parece, fazer uma teoria sobre o que é a ciência em geral sem associar-lhe uma questão histórica que, de certo modo, é uma sombra projetada" (FOUCAULT, 2016, p. 18-19). Ou seja, como pensar que está sendo valorizada um tipo de ciência, como algo verdadeiro e único, sem pensarmos o que está sendo colocado e projetado nessa relação.

Outro aspecto que nos chamou a atenção foram as referências a documentos e pesquisas internacionais, como forma de validar esse discurso científico. 
Com fundamento em evidências de pesquisas é possível determinar as melhores formas de promover o ensino de matemática básica (NATIONAL MATHEMATICS PANEL, 2008). E os professores, dada a importância que têm no processo de desenvolvimento da numeracia, precisam receber sólida formação em matemática elementar baseada em evidências científicas. (BRASIL, 2019a, p. 25 - grifos nossos)

Com o propósito de garantir o padrão de qualidade de suas iniciativas e a aplicação responsável dos recursos públicos, a PNA deu dois passos importantes: em primeiro lugar, propôs a definição de conceitos-chave (art. $2^{\circ}$, I a XI), a fim de evitar imprecisões e equívocos acerca da alfabetização, adotando termos como literacia e numeracia, em consonância com a terminologia comum presente nas pesquisas e estudos de países desenvolvidos; em segundo lugar, enunciou, entre seus princípios, condições que possibilitam a elaboração de uma política de alfabetização de maior eficácia (art. $3^{\circ}, \mathrm{III}$ a $\mathrm{V}$ ), a saber: a fundamentação em evidências das ciências cognitivas, a ênfase no ensino de seis componentes essenciais para a alfabetização consciência fonêmica, instrução fônica sistemática, fluência em leitura oral, desenvolvimento de vocabulário, compreensão de textos e produção de escrita - e a adoção de referenciais de políticas públicas exitosas, tanto nacionais quanto estrangeiras. (BRASIL, 2019a, p. 40, grifos nossos).

Não obstante, em determinadas passagens do documento vemos alguns pontos que, de certo modo, nos fazem pensar que a PNA busca, em certa medida, atribuir um caráter religioso à ciência quando valoriza passagens como esta:

Você já ouviu falar em Efeito Mateus? As crianças que adquirem desde cedo habilidades fundamentais para a alfabetização têm mais sucesso no processo de aprendizagem da leitura e da escrita e na vida escolar do que aquelas que não as adquirem. Esse fenômeno ficou conhecido na literatura especializada como Efeito Mateus, expressão que o cientista Keith Stanovich tomou emprestado da sociologia, inspirado na parábola dos talentos do Evangelho de São Mateus. Essa expressão passou a ser amplamente utilizada na literatura educacional para mostrar como as crianças com mais dificuldades em leitura no início do processo de alfabetização tendem a continuar a ter dificuldades ao longo da vida escolar. A consequência disso é que a distância entre os bons leitores e os maus leitores vai aumentando com o tempo: enquanto os bons leitores se sentem motivados a ler, e por isso leem mais, os maus leitores tendem a considerar a leitura algo tedioso e penoso, e portanto leem menos. Para aqueles a leitura vai-se tornando mais fácil, para estes mais difícil, agravando as desigualdades na trajetória escolar. (STANOVICH, 1986) (BRASIL, 2019a, p. 22).

A partir dessa concepção trazida na PNA de que existe uma única ciência e que, basear-se nela - a qual, é preciso dizer, não está clara no documento apresentado, embora traga o nome de ciência cognitiva - é a forma de solucionar os chamados problemas da alfabetização no Brasil e, ao mesmo tempo, garantia de alfabetizar as crianças no $1^{\circ}$ ano do Ensino Fundamental, sem considerar outros aspectos, nos direciona a chegar em outra categoria analítica: Onde está a cultura? Nota-se uma desconsideração de todo e qualquer tipo de referência ao processo de constituição histórica dos sujeitos, de aprendizagem e da própria alfabetização que não passe por essa única ideia de ciência.

Vemos que, no decorrer do documento, pontos como a valorização dos saberes populares, da cultura e de outras práticas, não estão citadas. Não obstante, as diferenças sócio-culturais, de acesso e de vulnerabilidade das famílias são desconsideradas como se, a partir de algumas poucas orientações, todos conseguissem realizar as mesmas práticas, reduzindo a problemática sócioeconômica.

As práticas de literacia familiar são especialmente importantes para a criança de até seis anos, mas podem e devem ir além, enquanto ela progride nos níveis de literacia com o estímulo e auxílio da família. Implementar programas e ações de literacia familiar como medidas preventivas do insucesso escolar tem sido uma estratégia empregada em diversos países. Esses programas e ações, em geral, objetivam encorajar pais ou cuidadores a desempenharem um papel mais 
ativo no desenvolvimento da literacia das crianças em idade pré-escolar. Os principais beneficiários são as famílias de nível socioeconômico mais baixo, cujas crianças se encontram em desvantagem com relação às demais (TUNMER, 2013; SÉNÉCHAL, 2008). Até mesmo pais ou cuidadores não alfabetizados podem realizar práticas simples e eficazes de literacia familiar quando bem orientados. (CARPENTIERI et al., 2011) (BRASIL, 2019a, p. 23 - grifos nossos).

Essas crianças terão mais possibilidades de obter sucesso no processo de alfabetização e de aprender a ler e escrever ao menos palavras e textos simples até o final do $1^{\circ}$ ano. Porém, como tais experiências de leitura e escrita estão muito associadas ao nível socioeconômico das famílias, se não houver uma atuação eficaz das escolas, principalmente das públicas, poderá abrir-se um fosso de aprendizagem entre as crianças de famílias mais favorecidas e as crianças de famílias menos favorecidas. Por isso é necessário ofertar a toda criança as condições que possibilitem aprender a ler e a escrever nos anos iniciais do ensino fundamental; daí a priorização da alfabetização no $1^{\circ}$ ano como uma das diretrizes da PNA.. (BRASIL, 2019a, p. 32 - grifos nossos)

Até mesmo adultos analfabetos, desde que informados sobre a importância de certas práticas e hábitos de leitura e escrita, podem cumprir decisivo papel na literacia familiar, ajudando a superar as deficiências do ambiente com práticas simples, como o manuseio de livros ilustrados, a contação de histórias, a entoação de cantigas tradicionais ou a participação com seus filhos em ambientes de literacia na própria comunidade. (BRASIL, 2019a, p.42 - grifos nossos).

Não há consideração sobre outros processos que não sejam essa chamada produção científica. Um afastamento de outras formas de pensar a constituição dos sujeitos que desconsidera, também, as condições de vulnerabilidade - de toda ordem - que acomete crianças e famílias brasileiras e dificultam o processo de alfabetização. A ideia de que com informação um adulto analfabeto pode colaborar no processo, nos faz questionar sobre o modo como esses informes chegarão até as comunidades e aos sujeitos cada vez mais desamparados pelo Estado. Fantasias meritocráticas rondam o documento na medida em que parece que todos podem obter aprendizagem e sucesso ao mesmo tempo. Um modo de governar, de conduzir as condutas, de constituir subjetividades com base em um conceito científico cognitivo visto como a verdade.

Destacamos as palavras de Foucault (2016), no curso Subjetividade e Verdade, quando aponta: "Trata-se de saber qual experiência podemos fazer de nós mesmos, qual campo de subjetividade pode abrir-se para o sujeito por ele mesmo, a partir do momento em que existe de fato, historicamente, diante dele, com relação a ele, determinada verdade, determinado discurso de verdade [...]" (FOUCAULT, 2016, p. 25-26). Problematizamos que, a partir de uma verdade de uma chamada ciência cognitiva, o sujeito pode se reconhecer como capaz ou incapaz de ser alfabetizado, visto que, na PNA, há uma garantia de que todos podem ser alfabetizados no $1^{\circ}$ ano do Ensino Fundamental. Assim, se o sujeito se curvar a essa força de verdade, sem refletir sobre suas demais condições culturais, sociais, econômicas, etc. - talvez, tenda a ser excluído do processo de escolarização.

\section{CONSIDERAÇÕES E CONCLUSÕES}

A partir das análises feitas percebemos que vem se anunciando outros modos de conduzir, considerar e constituir os corpos infantis dentro das escolas. Um deslocamento em relação ao que vinha sendo produzido em práticas e documentos governamentais precedentes. Num âmbito, nos perguntamos se, com esses novos modos de pensar o corpo infantil na escola, poderá ser garantida uma educação de qualidade para todos. É possível garantir que as diferenças de gênero, classe, 
questões étnico-raciais, deficiência, confessionalidades etc., sejam consideradas ao se planejar as aprendizagens dos sujeitos?

Como marcamos, até a década de 80 , o foco era que os sujeitos infatis se tornassem bons adultos, após, com o advento da sociologia da infância, passamos a ter uma centralidade na infância considerando todos os aspectos que a compõe, principalmente os sociológicos. Agora, o que vemos nessa Política Nacional de Alfabetização é a redução do corpo infantil a uma ideia biológica e cognitiva, desconsiderando outros aspectos. A forma de conduzir esses sujeitos, de governar a infância, parece estar se deslocando.

Ao pensarmos em governamento, faz-se importante lembrar que "nunca se governa um Estado, nunca se governa um território, nunca se governa uma estrutura política. Quem é governado são sempre pessoas, são homens, são indivíduos ou coletividades" (FOUCAULT, 2008a, p. 164). Nessa direção, procuramos problematizar que os sujeitos infantis estão sendo governados a partir de uma lógica que traz uma única ciência como verdadeira, que desconsidera as especificidades desses corpos e reduz a infância à uma compreensão única. Até então, em que pese a lógica da governamentalidade neoliberal, tinha-se como preocupação a inclusão de todos e tudo, entretanto, os novos rumos que se anunciam, parecem que podem limitar o acesso e permanência dos corpos na escola.

Portanto, o grande impacto desses novos caminhos que se anunciam nos preocupam e colocam em alerta os diferentes sujeitos do processo educativo brasileiro, uma vez que acreditamos ser fundamental preserver a pluralidade e as mais variadas possibilidades de diferença, ensino e aprendizagem que habitam o espaço escolar.

\section{REFERÊNCIAS}

1. ARIĖS, Philippe. História Social da Criança e da Família. Tradução Dora Flaksma. 2. ed. Rio de Janeiro: LTC, 2014.

2. BRASIL. Constituição da República Federativa do Brasil de 1988. Brasília, 1988. Disponível em: http://www.planalto.gov.br/ccivil_03/Constituicao/Constituicao.html.

3. BRASIL. Estatuto da Criança e do Adolescente. Lei no 8.096 de 13 de julho de 1990. Dispõe sobre o Estatuto da Criança e do Adolescente e dá outras providências. Brasília, DF, 1990.

4. Brasil. Ministério da Educação. Decreto n 9.765 de 11 de abril de 2019. Brasília : MEC, 2019.

5. Brasil. Ministério da Educação. Secretaria de Alfabetização. PNA Política Nacional de Alfabetização/Secretaria de Alfabetização. - Brasília : MEC, SEALF, 2019a. 
6. CASTRO, Edgardo. Vocabulário de Foucault. BH: Autêntica, 2009.

7. COELHO, Bernardo L. M. A proteção à criança nas constituições brasileiras: 1824 a 1969. In: Revista da Informação Legislativa. Brasília, 35 n. 139 jul/set, 1998.

8. FABRIS, Elí Terezinha Henn. A escola contemporânea: um espaço de convivência?. In: SILVA, Roberto Rafael Dias da (Org.). Currículo e docência políticas de ampliação da jornada escolar. Porto Alegre : Evangraf, 2014, p. 47-66. ISBN 978-85-7727-688-2.

9. FOUCAULT, Michel. Foucault. O Retorno da Moral. In: FOUCAULT, Michel. Ditos e Escritos, vol. V, Foucault: Ética, Sexualidade, Política. Ed. Forense Universitária, $1^{a}$ ed, 2004, p. 234-239.

FOUCAULT, Michel. Nascimento da Biopolítica. São Paulo: Martins Fontes, 2008.

11. FOUCAULT, Michel. Segurança, Território e População. São Paulo: Martins Fontes, $2008 \mathrm{a}$.

12. FOUCAULT. Michel. Em Defesa da Sociedade. São Paulo: Martins Fontes, 2010.

13. FOUCAULT. Michel. Subjetividade e Verdade. São Paulo: Martins Fontes, 2016.

14. GALLO, S. Sob o signo da diferença: Em torno de uma educação para a singularidade. In: SILVEIRA, R. (Org.). Cultura, poder e educação: um debate sobre Estudos Culturais em Educação. Canoas: Ed. ULBRA, 2005. p.211-223.

KOHAN, Walter Omar. A infância da educação: o conceito devir-criança. In: Lugares da infância: filosofia. Rio de Janeiro: DP\&A, p. 51-68, 2004.

16. LOPES, Maura; FABRIS, Eli. Inclusão e educação. Belo Horizonte: Autêntica, 2013.

17. NARODOWSKI, Mariano. Infância e poder: conformação da pedagogia moderna. Bragança Paulista: Universidade São Francisco, 2001.

18. RIO GRANDE DO SUL (Estado). Lei estadual n. 12.544, de 3 de julho de 2006. Institui o Programa Primeira Infância Melhor - PIM. Porto Alegre, RS, Ministério Público. Disponível em: http://www.pim.saude.rs.gov.br/v2/.

19. SARMENTO, Manuel Jacinto. Gerações e alteridade: interrogações a partir da sociologia da infância. In: Educação e Sociedade. Campinas, vol. 26, n. 91, p. 361-378, Maio/Ago. 2005. 
SILVA, Tomaz Tadeu da. "Adeus às Metanarrativas Educacionais". In: (Org.). O Sujeito da Educação: estudos foucaultianos. Petrópolis: Vozes, 1994. p. 247-258.

21. SCHEINVAR, Estela. "A aplicação do ECA tem se desviado da sua proposta original": Estado de Direito e formação discursiva no campo da criança e do adolescente. In: RESENDE, Haroldo (org.). Michel Foucault e o governo da infância. Belo Horizonte: Autêntica Editora, 2015, p. 103-113

22. VEIGA-NETO, Alfredo. Coisas do governo... In: RAGO, Margareth; ORLANDI, Luiz B. Lacerda; VEIGA-NETO, Alfredo (orgs.). Imagens de Foucault e Deleuze: ressonâncias nietzschianas. Rio de Janeiro: DP\&A, 2002, p. 13-34.

23. VEIGA-NETO, Alfredo. Educação e Contemporaneidade: um olhar foucaultiano. In: BOTH, Valdevir; CARBONARI, Paulo César (org.). Michel Foucault: diálogos sobre política, educação e ética. Passo Fundo: IFIBE, 2016. p.37-48. ISBN: 978-85-8259-037-9.

24. WITTGEINSTEN, Ludwig. Investigações fiolosófica. São Paulo: Editora Nova Cultural Ltda, 1999.

\section{Isabela Dutra}

Doutora e Mestre em Educação pela Universidade Federal do Rio Grande do Sul. Coordenadora Pedagógica no Colégio Americano (Porto Alegre).

\section{Roseli Belmonte Machado}

Professora Adjunta na Universidade Federal do Rio Grande do Sul (UFRGS) na Escola de Educação Física, Fisioterapia e Dança.

\section{Como citar este documento:}

DUTRA, Isabela; MACHADO, Roseli Belmonte. Corpos infantis na contemporaneidade: deslocamentos e subjetividades na política nacional de alfabetização. Reflexão e Ação, Santa Cruz do Sul, v. 28, n. 2, june 2020. ISSN 1982-9949. Disponível em: $<$ https://online.unisc.br/seer/index.php/reflex/article/view/14418>. Acesso em doi:https://doi.org/10.17058/rea.v28i2.14418. 